Acta Crystallographica Section D

Biological

addenda and errata

Crystallography

ISSN 0907-4449

\title{
The atomic resolution structure of bucandin, a novel toxin isolated from the Malayan krait, determined by direct methods. Erratum
}

\section{Peter Kuhn, ${ }^{a}$ Ashley M. Deacon, ${ }^{\text {a Doina-Silviana Comsa, }}{ }^{\text {b }}$ G. Rajaseger, ${ }^{\mathrm{c}}$ R. Manjunatha Kini, ${ }^{\mathrm{C}}$ Isabel Usón ${ }^{\mathrm{d}}$ and Prasanna R. Kolatkar ${ }^{\mathrm{b} *}$}

${ }^{a}$ Stanford Synchrotron Radiation Laboratory, SLAC, PO Box 4349, MS69, Stanford University, Stanford, CA 94309, USA, 'bnstitute of Molecular and Cell BiologyBioinformatics Centre, 30 Medical Drive, Singapore 117609, Singapore, ${ }^{\mathrm{c} B i o s c i e n c e}$ Centre, Faculty of Science, NUS, Singapore 119260, Singapore, and Institute of Inorganic Chemistry, Tammannstrasse 4, 37077 Göttingen, Germany

In the paper by Kuhn et al. [Acta Cryst. (2000), D56, 1401-1407] the name of the third author was given incorrectly. The correct name should be Doina-Silviana Comsa as given above. 